BMJ Open Sport \& Exercise Medicine

\title{
Sibling influence on children's objectively measured physical activity: a meta-analysis and systematic review
}

\author{
Chelsea L Kracht, Susan B Sisson
}

To cite: Kracht CL, Sisson SB. Sibling influence on children's objectively measured physical activity: a meta-analysis and systematic review. BMJ Open Sport \& Exercise Medicine 2018;4:e00405. doi:10.1136/ bmjsem-2018-000405

Accepted 20 June 2018
Check for updates

\section{(C) Author(s) (or their} employer(s)) 2018. Re-use permitted under CC BY-NC. No commercial re-use. See rights and permissions. Published by BMJ.

Department of Nutritional Sciences, College of Allied Health, University of Oklahoma Health Sciences Center, Oklahoma City, Oklahoma, USA

Correspondence to Dr Susan B Sisson; susansisson@ouhsc.edu

\section{ABSTRACT}

Children without siblings (only children) have higher rates of obesity than children with siblings. Childhood obesity may be prevented by minimising sedentary behaviour and accumulating sufficient physical activity in young children. A growing number of articles have examined the influence of siblings on physical activity and sedentary behaviour, yet these articles have not been synthesised.

Objective To synthesise literature and describe the influence of siblings on objectively measured physical activity and sedentary behaviour of children (ages 2-18 years).

Design Outcomes were analysed in a systematic review and meta-analysis.

Data sources PubMed, EMBASE, Web of Science and Medline OVID were searched for articles related to siblings, physical activity, sedentary behaviour and obesity outcomes from 1947 to March 2018.

Eligibility criteria Articles that evaluated sibling status on physical activity objectively measured by accelerometer or pedometer were included.

Results Nineteen articles, representing 17 independent datasets, were included in the review. Nine were included in the quantitative analysis. Pooled data from nine articles indicated children with siblings had higher moderate-to-vigorous physical activity (MVPA) relative to only children, with a potential dose response for higher number of children in household and higher MVPA (Mean Difference $=3.13,95 \% \mathrm{Cl} 1.90$ to $4.35, \mathrm{p}=0.001)$. Findings were mixed for the influence of siblings on sedentary behaviour and light physical activity.

Summary/Conclusion Children with siblings had healthier physical activity patterns, as measured by accelerometer or pedometer, than did only children. Suggested mechanisms include peer modelling, encouraging active transport and sports participation, opportunity for playmate and serving as additional caregivers. Trial registration number CRD42017055463.

\section{INTRODUCTION}

Physical activity is essential for optimal health and development in children and can positively contribute to prevention of excess weight gain, ${ }^{1}$ cognitive performance, ${ }^{2}$ motor development $^{3}$ and psychosocial health. ${ }^{4}$ Modes of physical activity that often create beneficial moderate-to-vigorous physical activity
What is already known?

Children without siblings have higher rates of obesity than children with siblings.

- Siblings have a unique influence on behaviour since they are a persistent influence as both a peer and a family member.

- The difference in obesity rates between children without siblings and children with siblings is around 8 years old, when moderate-to-vigorous physical activity (MVPA) levels may also be declining.

\section{What are the new findings?}

Children with siblings had higher MVPA compared with only children.

- There was a potential dose response where with more siblings, children had more MVPA.

- Findings were mixed for sedentary behaviour and light physical activity.

- Potential mechanisms for children with siblings to increase MVPA include active transport, sports participation and peer modelling.

How might it impact on clinical practice in the near future?

These findings provide additional evidence for treating the family rather than the individual for encouraging physical activity behaviours.

- Children without siblings may be at risk for less MVPA and may need more encouragement or peer support for MVPA relative to children with siblings.

- Siblings serve as an important person to model health habits and could be used as a motivator to participate in active transport and sports.

- Sibling rivalry may still influence a sibling's view on sport participation and may need to be considered when evaluating a child's sports preferences.

(MVPA) include sports participation, ${ }^{56}$ active transport $^{7}$ and outdoor recreation. ${ }^{8}$ In the socioecological model, a theory of behaviour denoting the multiple layers of influence on an individual's behaviours, parents, peers and siblings are in the microsystem and 
shape development of children's behaviours through multiple mechanisms. ${ }^{9}{ }^{10}$ Physical activity of parents is associated with higher child MVPA through coparticipation and encouragement of activity. ${ }^{11}$ However, parental preferences and time and household demands may also encourage children to participate in sedentary behaviour, such as TV watching. ${ }^{12}$ Aspects of peer support that have been previously associated with higher physical activity include peer involvement, ${ }^{13}$ peer mentoring ${ }^{14}$ and friendship derived from team sports participation. ${ }^{15}$

Siblings are an important influence on physical activity because they may exhibit a composite of the parent's health behaviours, ${ }^{16}$ while also serving as a similar age companion, or peer, for physical activity and sedentary behaviour. Similar to peers, siblings may increase MVPA through coparticipation and social support, ${ }^{17} 18$ but they can also persuade each other to coparticipate in sedentary pursuits, including television viewing or electronic media use. ${ }^{19}{ }^{20}$ Unlike friends or peers, siblings are a constant and prolonged presence in the child's life ${ }^{21}$ and may serve as supervision in the parent's absence, thus acting as a parental influence. This continued influence may lead to more unstructured opportunities for physical activity ${ }^{22}$ or sedentary behaviour. ${ }^{23}$ However, there are still many gaps in the literature regarding the influence of the sibling on both child physical activity and sedentary behaviour. ${ }^{24}$

As it pertains to health outcomes, children without siblings (only children) have a higher rate of obesity than do children with siblings. ${ }^{25}$ Since excess weight gain has been related to lower MVPA and elevated sedentary behaviour, ${ }^{26}{ }^{27}$ this difference in obesity rates and energy balance suggests that the presence of siblings may support more MVPA and less sedentary behaviour. Further, the split in obesity rates between only children and children with siblings emerges at around 8 years old, ${ }^{28}$ when MVPA levels start to decline in children. ${ }^{29}$ Since siblings are a persistent influence throughout childhood, their preferences at this stage may perpetuate or deter this decline in MVPA. ${ }^{30}$ Moreover, into adolescence (around 12 years old), children spend more time with their peers, and peers become a greater influence on physical activity than parents. ${ }^{31}$ During this time, the sibling influence on physical activity as a family member may be tempered, but the peer influence of a sibling may contribute to healthier physical activity patterns. ${ }^{32}$ While the literature including siblings as a covariate and specifically designed to examine siblings is growing, an understanding of the collective influence of siblings on child physical activity and sedentary behaviour is difficult to distil from the literature. The purpose of this article is to synthesise the literature and describe the influence of siblings on objectively measured physical activity and sedentary behaviour of children in a systematic review and meta-analysis.

\section{METHODS}

\section{Study selection}

A search of PubMed, MEDLINE, EMBASE and Web of Science databases was conducted using studies published in the English language from 1947 through February 2017. The search terms included 'siblings' (or other database specific variations, such as family circumstance, family situation, only child) and variations of terms for energy balance-related health behaviours (screen time, sedentary behaviour, exercise, physical activity and dietary intake) and weight outcomes (waist circumference, body mass index and anthropometry). Observational, experimental and qualitative studies were originally included. After reviewing the total number of studies retrieved from the broad search, the authors refined the search to only physical activity-related outcomes. A second search was conducted in March 2018, including siblings search terms (including sibling, family circumstance and family structure) and variations of terms for physical activity (including physical activity, exercise and sedentary lifestyle), to update the results. No additional articles were retrieved at that time. References lists of included studies were searched for additional articles. The study was performed in accordance with the Preferred Reporting Items for Systematic Reviews and Meta-Analysis (PRISMA). ${ }^{33}$ The protocol was registered with the National Institute for Health Research International prospective register of systematic reviews (PROSPERO - CRD42017055463).

\section{Population}

Studies of children (ages 2-18 years) without chronic conditions were included. Cross-sectional, longitudinal and intervention studies addressing obesogenic behaviours (screen time, physical activity and dietary intake) or weight outcomes (waist circumference, body mass index and anthropometrics) were included in the search. Studies were excluded if they were twin studies, adult sibling (18 years or older) studies, studies with children who have a sibling with a chronic disease (such as paediatric cancer) or acute conditions (such as urinary tract infections) and studies with a discordant sibling analysis or using the sibling as a matched control. Twin sibling relationships have different characteristics, and twins are more alike genetically than non-twin siblings; these variances may confound any relationship between only-child status and the outcomes of obesogenic behaviours and anthropometry. ${ }^{34}$ Studies comparing between siblings (such as discordant weight comparisons) or within siblings sets (such as within the same family) are used to eliminate the potential risk of genetic differences, test the family function and birth order and exclude only children from analysis. ${ }^{35}$ Further, children with a chronic disease or who have a sibling with a chronic disease may not have typical interactions or relationships. ${ }^{36}$

\section{Data abstraction}

The main author (CLK) screened abstracts of studies retrieved ( $n=10978)$. The full text of potentially eligible studies $(n=709)$ was retrieved and independently assessed for eligibility by the main author (CLK), and the eligible studies were reviewed by the second author (SBS) $(n=19)$. Any disagreement over the eligibility of particular studies was resolved through discussion. A standardised, piloted 
form was used to extract data from the full-text studies for assessment evidence synthesis and study quality $(n=19)$. Extracted information included study setting, study population, participant demographics and baseline characteristics, study methodology, recruitment and study completion rates, outcomes and times of measurement, conclusions on sib-ship, suggested mechanisms involving siblings and the outcomes and information for assessment of the risk of bias. A modified Nutrition Evidence Library Bias Assessment Tool (NELBAT) form was used to address risk of bias on the study level, including similar recruitment strategy across groups, controlling for known confounders and use of valid and reliable measures. ${ }^{37}$ The form was modified to specifically address the comparison between only children and children with siblings as groups and any baseline differences between these two groups (Example: Question 1 assessed whether the inclusion/exclusion criteria were similar between only children and children with siblings). Of the selected studies, all extracted information was reviewed by the second assessor of risk of bias (SBS), and any discrepancies were identified and resolved through discussion.

\section{Statistical analysis}

The mean differences or standardised beta coefficients were obtained through article reports or by calculating the mean difference between only children and children with siblings. It was previously reported that standardised beta coefficients are sufficient for meta-analysis comparisons. ${ }^{38}$ When multiple estimates were available, the most adjusted or most parsimonious model estimates were used for comparison. All analysis was conducted with a random effects model. Heterogeneity was determined using the $\mathrm{I}^{2}$ statistic, with a larger value indicating larger amounts of heterogeneity. ${ }^{39}$ Publication bias was assessed visually using funnel plots. Subgroup analyses were conducted using age and sex, due to their influence on interpretation of obesogenic outcomes. Due to the heterogeneity of sibling classification, comparisons made in the meta-analysis were: (1) only children and children with siblings; (2) no older siblings and the presence of older siblings, along with respective comparison for younger siblings and (3) number of children. In addition, subgroup analysis was conducted, including: (4) male and female and (5) older (older than 10 years old) and younger children (under 10 years old). Due to the heterogeneity of outcomes, only MVPA/day was used for subgroup analysis. All analysis was conducted using the Cochrane Review Manager 5.3 Software (The Cochrane Collaboration, Copenhagen, Denmark).

\section{RESULTS}

Due to the breadth of full-text articles obtained after the initial search and screened abstracts $(n=666)$, the authors realigned the focus of the analysis from all obesogenic behaviours to objectively measured physical activity (use of an accelerometer or pedometer). The second search in March 2018 of only physical activity outcomes retrieved 463 additional unique records, and 43 records for full text review ( $n=709$, figure 1). Other forms of assessing physical activity removed during full-text review $(\mathrm{n}=95)$ included qualitative analysis $(\mathrm{n}=29)$, general physical activity $(\mathrm{n}=23)$, active commuting $(\mathrm{n}=14)$, sports participation $(n=9)$, family physical activity $(n=5)$, questionnaire physical activity $(n=5)$, general exercise $(n=4)$, outdoor time $(\mathrm{n}=2)$ and other various physical activity behaviours $(n=3)$. Three additional studies were identified from manually searching references. With the final 19 studies, ${ }^{40-58}$ the authors investigated duplication of results from large cohorts. In the case when multiple papers were published using the same data, the most recent publication was used for quantitative comparisons. Due to the heterogeneity in reporting of siblings and physical activity, only nine articles were compared quantitatively in the meta-analysis. ${ }^{40} 4144-4751555759$

Of the 19 articles included, most articles were cross-sectional $(n=16)$, represented developed countries $(n=19)$, collected data after the year $2000(\mathrm{n}=18)$ and reported a low risk of bias (NELBAT score less than 3: $n=14$ ) (table 1). Most articles recruited from school settings $(n=15)$, required the children to wear the activity monitor for at least 3 days $(n=7)$ or 4 days $(n=5)$ (at least 1 weekend day) with 10 hours of wear each day to be included in analysis and performed multilevel linear regression or clustering analysis to account for the similarities within schools $(n=15)$. With the differing outputs of physical activity, such as min/hour or per cent time, and varying evaluation of sibling composition, such as only child or number of siblings, few point estimates compared directly. A summary of the results is displayed in table 2. Overall, there were mixed results for siblings on sedentary behaviour $(n=9)$, with the intervention not favouring siblings, two articles reporting non-significant results, three articles with mixed results or subgroup-specific results and three articles that favoured siblings. Mixed results continued when comparing the articles investigating light physical activity, with reports.

\section{Only children and children with siblings}

When quantitatively comparing only children with children with siblings on MVPA min/day ( $n=3)$, children with siblings exhibited higher MVPA min/day (Estimate $=5.18$, $95 \%$ CI 1.05 to $9.32, \mathrm{p}=0.01$ ), with mild heterogeneity between the articles included $\left(\mathrm{I}^{2}=36 \%\right)$ and a significant effect $(\mathrm{Z}=2.46, \mathrm{p}=0.01$, data not shown). There were no consistent LPA or sedentary behaviour outcomes to compare across studies for only children versus children with siblings.

\section{Older and younger siblings}

Two articles compared the presence of older siblings with similar age (within 3 years) or no older siblings on MVPA min/day. The articles reported that children with older siblings had more MVPA min/day (Estimate $=6.87$, $95 \%$ CI 2.38 to $11.36, \mathrm{p}=0.003$ ) with little heterogeneity between the articles $\left(I^{2}=0 \%, Z=3.00, p=0.003\right.$, data not 


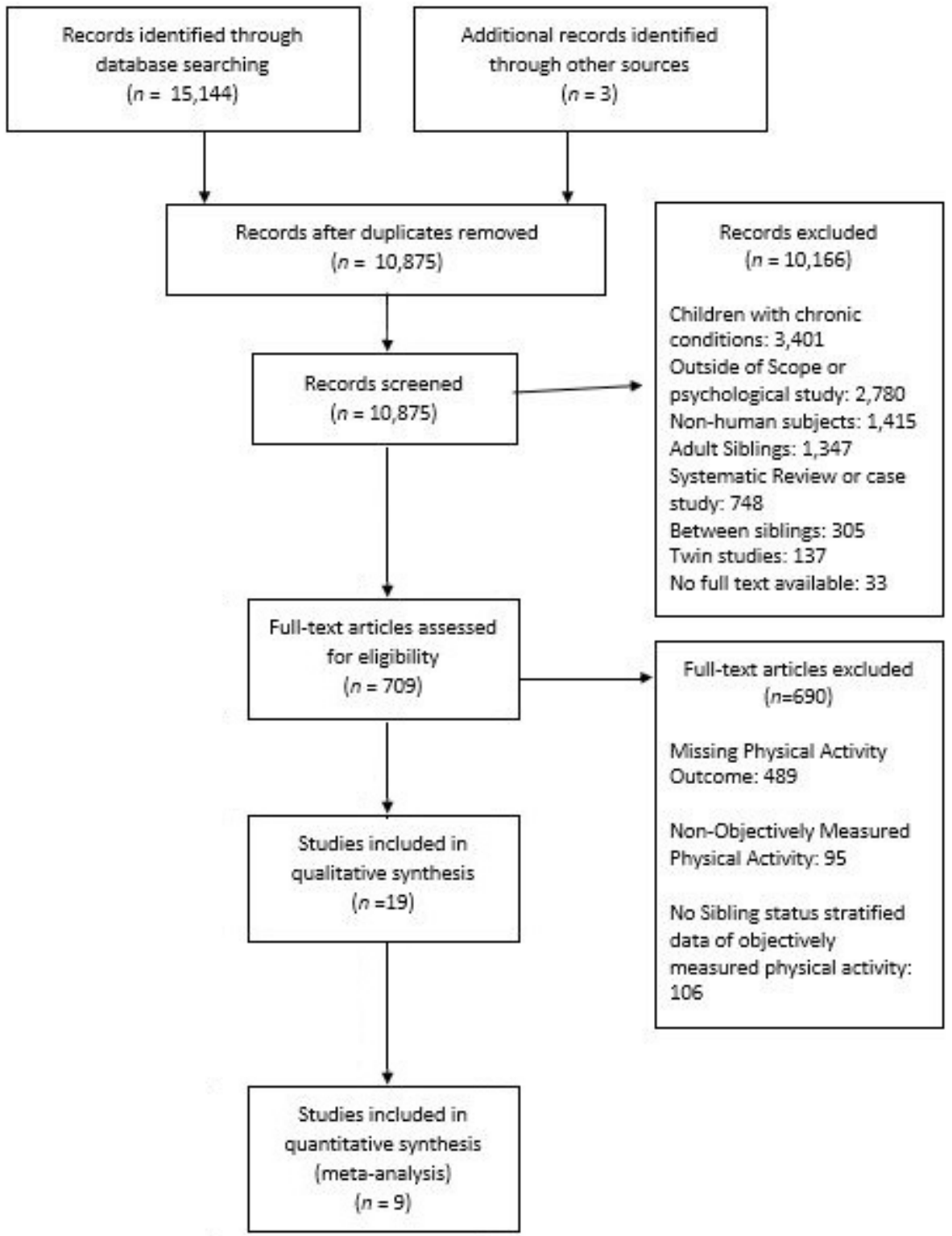

Figure 1 PRISMA flowchart of studies included in meta-analysis. PRISMA, Preferred Reporting Items for Systematic Reviews and Meta-Analysis.

shown). ${ }^{47}$ As the sole article to quantitatively address older and younger siblings on sedentary behaviour, Hnatiuk et $a t^{43}$ reported that children with older $(\beta=-1.96$, $95 \%$ CI -4.23 to 0.32$)$ and younger siblings $(\beta=-2.03$, $95 \%$ CI -4.38 to 0.32 ) had less sedentary behaviour per hour than did only children.

\section{Number of siblings}

Only two articles from the same cohort reported the influence of number of siblings on sedentary behaviour, ${ }^{4142}$ which indicated that with more siblings, there is less sedentary behaviour. Further, more siblings contributed to more MVPA per day, with the resulting estimate of $3.13 \mathrm{~min}$ of MVPA per sibling (95\% CI 1.90 to $4.35, \mathrm{p}<0.01$ ) and little heterogeneity between the studies $\left(\mathrm{I}^{2}=0 \%\right.$, figure 2$)$. McMinnet al (2011) evaluated the number of siblings and CPM and found there was an interaction by ethnicity.
According to McMinn, ${ }^{58}$ in white Europeans there was a positive association between number of siblings and CPM (per sibling $10.3,95 \%$ CI (1.7 to 18.9$), \mathrm{p}<0.05)$, but the association was not significant in black African Caribbean (per sibling $=3.5,95 \%$ CI $(-4.2$ to 11.2$)$ ) and South Asians (per sibling $-6.0,95 \% \mathrm{CI}-15.5$ to 3.4$){ }^{44}$

\section{Males and females}

There was a significant effect of having siblings on MVPA for males and no significant effect of siblings on MVPA for females. There were no subgroup differences between males and females, indicating there is no direct difference across groups in the influence of siblings and no differential response to having siblings (figure $3 \mathrm{~A}$ ). There were only two articles with available homogenous measures (MVPA min/day). ${ }^{40} 46$ Therefore, this result differs from the summary of findings table (table 2). 
Table 1 Characteristicsof included studies assessing siblings on objectively measured physical activityoutcomes $(\mathrm{n}=19)$

\begin{tabular}{|c|c|c|c|c|c|c|}
\hline Firstauthor, Year & Country & Age* $^{*}$ & Sample & Setting/Cohortname & Timeperiod & NELBAT \\
\hline \multicolumn{7}{|l|}{ Crosssectional } \\
\hline Bagley et al, ${ }^{57} 2006$ & Australia & $5-6,10-11$ & 1180 & Elementaryschools & Jul 2001-Dec 2001 & 3 \\
\hline Byun et $a l,{ }^{53} 2011$ & USA & $4.3 \pm 0.6$ & 331 & CHAMPS & Aug 2003-Jan 2006 & 3 \\
\hline Gomes et al, ${ }^{42} 2014$ & Portugal & $9-10$ & 686 & ISCOLE & Sep 2011-Jan 2013 & 3 \\
\hline Gomes et al, ${ }^{41} 2017$ & Portugal & $9-11$ & 499 & ISCOLE & Sep 2011-Jan 2013 & 3 \\
\hline Hesketh et al, ${ }^{46} 2006$ & Australia & $5-6,10-11$ & 2458 & CLAS and HEPS & $2001-2003$ & 3 \\
\hline Hinkley et al, ${ }^{52} 2012$ & Australia & $3-5$ & 705 & HAPPY & Jul 2008-Oct 2009 & 3 \\
\hline Hnatiuk et al, ${ }^{43} 2016$ & England & $3-4$ & 120 & SPACE & Jan 2013-Jun 2013 & 3 \\
\hline McMinn et al, ${ }^{44} 2011$ & England & $9.9 \pm 0.4$ & 2071 & CHASE & Jan 2006-Feb 2007 & 1 \\
\hline McMinn et al, ${ }^{58} 2013$ & England & $10.3 \pm 0.3$ & 1608 & SPEEDY & Apr 2007-Jul 2007 & 3 \\
\hline Mitchell et $a l,{ }^{40} 2016$ & Canada & $9-14$ & 435 & STEAM & $\begin{array}{l}\text { Spring 2011-Spring } \\
2013\end{array}$ & 3 \\
\hline Pearce et $a l,{ }^{54} 2014$ & UK & $10.7 \pm 0.5$ & 427 & PEACH & Sep 2006-Jul 2008 & 5 \\
\hline Pouliou et $a l,{ }^{48} 2015$ & UK & 7 & 6497 & MCS & May 2008-Aug 2009 & 6 \\
\hline Tandon et al, ${ }^{51} 2014$ & USA & $9.2 \pm 1.6$ & 713 & NIK & Sep 2007-Jan 2009 & 3 \\
\hline Van Sluijs et al, ${ }^{47} 2013$ & UK & 4 & 487 & SWS & Mar 2006-Jun 2009 & 4 \\
\hline Wang and Qi, ${ }^{45} 2016$ & China & $10-16$ & 612 & $\begin{array}{l}\text { Primaryandsecondary } \\
\text { schools }\end{array}$ & Not described & 4 \\
\hline Wijtzes et al, ${ }^{50} 2013$ & Netherlands & $25 \pm 1$ months & 347 & Generation R Study & Dec 2005-Feb 2008 & 3 \\
\hline \multicolumn{7}{|l|}{ Longitudinal } \\
\hline Atkin et $a l,{ }^{49} 2013$ & England & $10.2 \pm 0.3$ & 854 & SPEEDY & Apr 2007-Jul 2008 & 3 \\
\hline Crawford et al, ${ }^{55} 2010$ & Australia & $10-12$ & 301 & CLAN & Jul 2001-Dec 2006 & 1 \\
\hline \multicolumn{7}{|l|}{ Intervention } \\
\hline Verloigne et al, ${ }^{56} 2012$ & Belgium & $10-12$ & 372 & UP4FUN Pilot & Sep 2011-Jan 2012 & 10 \\
\hline
\end{tabular}

*Values presented aremeans \pm SDor range of participants age (years), unless otherwise indicated. For longitudinal and intervention studies, age at baseline is presented.

CHAMPS, Children's Activity and Movement in Preschool Study;CHASE, Child Heart And health Study in England;CLAN, Children Living in Active Neighbourhoods;CLAS, Children's Leisure Activities Study;HAPPY, Healthy Active Preschool Years Study;HEPS, Health, Eating and Play Study;ISCOLE, International Study of Childhood Obesity, Lifestyle and the Environment;MCS, Millennium Cohort Study; NELBAT,NutritionEvidence Library Bias Assessment Tool;NIK, Neighborhood Impact on Kids Study; PEACH, Personal and Environmental Associations with Children's Health;SPACE, Studying Physical Activity in preschool aged Children and their Environment;SPEEDY, Sport, Physical activity and Eating Behavior Environmental Determinants on Young people; STEAM, Spatial Temporal Environment and Activity Monitoring;SWS, Southampton Women's Survey.

\section{Older and younger children}

In subgroup analysis by age (figure 3B), the magnitude of effect for children older than 10 years was smaller, yet still significant $(\mathrm{p}=0.04)$, with no differences between subgroups $(\mathrm{p}=0.18)$, but moderate heterogeneity in the older children $\left(\mathrm{I}^{2}=42 \%\right)$. Therefore, across all ages, children with siblings had more MVPA min/day than only children. This result was sustained when comparing all studies (table 2).

\section{DISCUSSION}

In summary, there is moderate quantitative evidence that children with siblings exhibit more MVPA than only children, with qualitative synthesis reporting mixed results between the groups on LPA and sedentary behaviour. In the meta-analysis, children with siblings had a slight overall increase in MVPA per day, an average five more minutes MVPA/day than only children. There may be a possible dose-response, with more siblings leading to more child MVPA and less sedentary behaviour. For each additional sibling, there were 3.13 more minutes of MVPA per day. In the longitudinal studies, there was no consistent direction on sibling's influence on change in physical activity, and the sole intervention study hypothesised that siblings may influence the efficacy of their efforts to reduce SB. When evaluating demographics, children with siblings continued to have higher MVPA than did only children, regardless of sex or age. It may be important to evaluate the role of siblings in facilitating physical activity or sedentary behaviour in young children to ensure that all children are physically active.

\section{Modes of physical activity}

As a part of this investigation, the authors focused on objectively measured physical activity. However, as addressed above, physical activity can also be measured by sports participation, active commuting and qualitative 
Table 2 Summary offindings ofstudiesassessingsiblings onobjectivelymeasuredphysicalactivityoutcomes $(\mathrm{n}=19)^{\star}$

\section{Physicalactivityoutcomes}

\begin{tabular}{|c|c|c|c|c|}
\hline \multirow[b]{2}{*}{ Studies } & \\
\hline & SB & LPA & MVPA & CPM \\
\hline \multicolumn{5}{|l|}{ Crosssectional } \\
\hline Bagleyet al, ${ }^{57} 2006$ & - & - & Favourssiblings & - \\
\hline Byunet al, ${ }^{53} 2011$ & NS & - & - & - \\
\hline Gomeset al, ${ }^{42} 2014$ & Favourssiblings & - & - & - \\
\hline Gomeset al, ${ }^{41} 2017$ & Favourssiblings & - & Favourssiblings & - \\
\hline Heskethet $a l,{ }^{46} 2006$ & M-NS/F-favourssiblings & Does notfavoursiblings & M-NS/F-favourssiblings & - \\
\hline Hinkleyet al, ${ }^{52} 2012$ & - & M-NS/F-favourssiblings & M-NS/F-favourssiblings & - \\
\hline Hnatiuket al, ${ }^{43} 2016$ & NS & - & NS & - \\
\hline McMinnet al, ${ }^{44} 2011$ & - & - & - & Favourssiblings \\
\hline McMinn,2012 & - & - & Favourssiblings & - \\
\hline Mitchellet al, ${ }^{40} 2016$ & - & - & M-favourssiblings/F-NS & - \\
\hline Pearceet al, ${ }^{54} 2014$ & - & - & M-NS/F-favourssiblings & - \\
\hline Pouliouet al, ${ }^{48} 2015$ & - & - & NS & NS \\
\hline Tandonet al, ${ }^{51} 2014$ & Mixedresults & - & Favourssiblings & - \\
\hline Van Sluijset al, ${ }^{47} 2013$ & - & NS & $\begin{array}{l}\text { Favours onlyolder } \\
\text { siblings }\end{array}$ & - \\
\hline Wanget al,2015 & - & - & NS & - \\
\hline Wijtzeset al, ${ }^{50} 2013$ & Favours only $2+$ & - & Favours only $2+$ & Favours only $2+$ \\
\hline \multicolumn{5}{|l|}{ Longitudinal } \\
\hline Atkinet $a l,{ }^{49} 2013$ & Favourssiblings & - & - & - \\
\hline Crawfordet al, ${ }^{55} 2010$ & - & - & M-NS/F-favourssiblings & - \\
\hline \multicolumn{5}{|l|}{ Intervention } \\
\hline Verloigneet al, ${ }^{56} 2012$ & Does notfavoursiblings & NS & NS & - \\
\hline
\end{tabular}

${ }^{*} \mathrm{NS}=$ no significant difference between children with siblings and only children;Favourssiblings = results found favoured the presence of siblings (ie, increased LPA or MVPAor CPMor decreased SB);Does not favoursiblings=results found did not favour the presence of siblings (ie, decreased LPA or MVPA or CPMor increased SB);M-NS/F-favourssiblings = NS result for boy's physical activity outcomes, Favours siblings for girl's physical activity outcomes;M-favourssiblings/F-NS =favours sibling result for boy's physical activity outcomes, NS result for girl's physical activity outcomes;Mixed results =results that favoured siblings (less SB) and results that did not favour siblings (more SB) were found, Favours onlyoldersiblings=results indicated that only older siblings improved physical activity outcomes; Favours only $2+=$ results indicated that having greater than two siblings improved physical activity outcomes.

CPM,counts per minute;LPA,light physical activity;MVPA,moderate-to-vigorous physical activity;SB,sedentary behaviour;SED,sedentary behaviour.

analysis (interviews and focus groups). When comparing all included articles to studies that operationalised physical activity through methods other than accelerometer and pedometer, the authors found evidence that children with siblings had more MVPA and that siblings influence children's sedentary opportunities. Articles retrieved on sports participation reiterated the sibling's positive influence ${ }^{5960}$ with most signifying that sibling's existing sports participation positively influences the child's involvement in sports. ${ }^{136162}$

China is a country with a larger one-child population. In studies from China, there are conflicting results

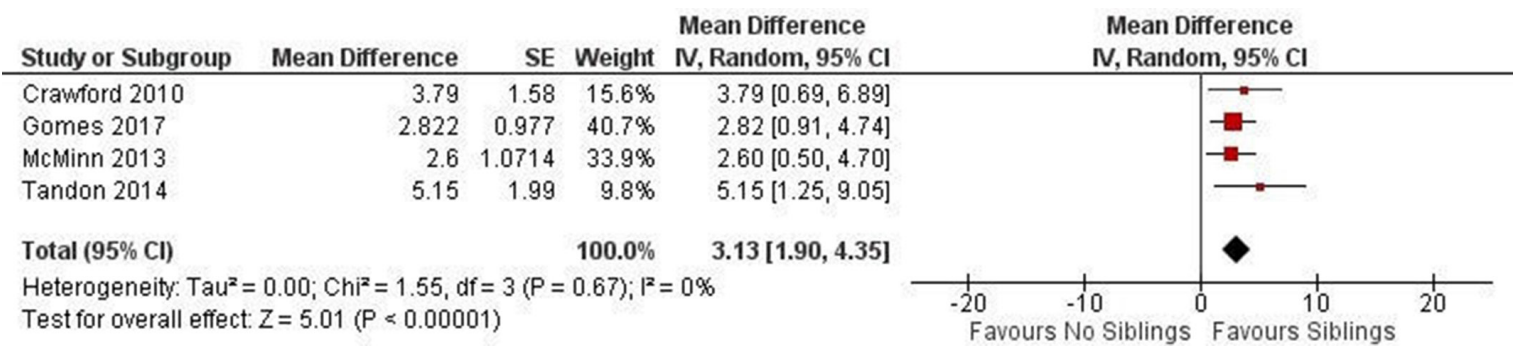

Figure 2 Comparison of number of siblings on objectively measured MVPA min/day. MVPA, moderate-to-vigorous physical activity. 


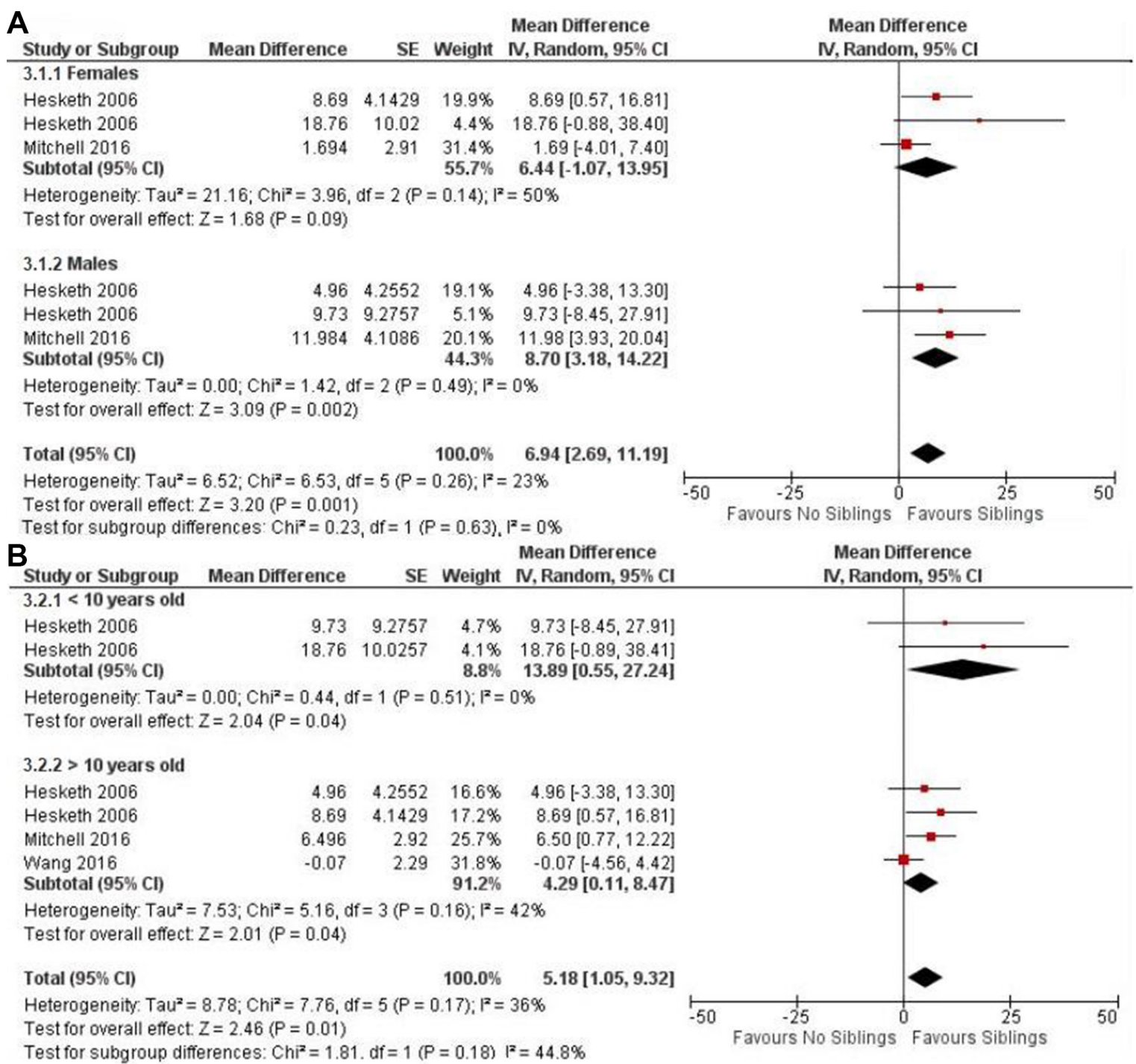

Figure 3 Subgroup analyses of only children and children with siblings on objectively measured MVPA min/day. MVPA, moderate-to-vigorous physical activity.

between only children and children with siblings in sports participation ${ }^{63}{ }^{645}$ and sedentarybehaviour. ${ }^{65} \mathrm{Au}-$ thors note the priority of scholastic work, and the higher parental expectations of academic achievement for only children in China driving this difference. ${ }^{64} \mathrm{~A}$ few articles mentioned that sibling coparticipation in sports and activity may breed rivalry or jealousy between the chil$\operatorname{dren}^{66}$ and forced interaction for the child, ${ }^{67}$ accordingly creating negative feelings towards physical activity.

In qualitative studies, children identified siblings' preferences for sedentary activities as a deterrent to being active ${ }^{68}$ or forgoing physical activity due to their incompatible skill levels in the activity ${ }^{69}$; noting that the sibling was not at the same developmental level as they were in sport, in most cases citing that the younger sibling was not at the same level. Parents also felt that older siblings who engage in more screen time have the potential to be a negative influence on the sedentary behaviours of younger siblings. ${ }^{61}$ Children with siblings participate in more active transportation $^{70} 71$ and time in open space, such as parks, ${ }^{72}$ with few studies reporting no association with sibling status. ${ }^{73-75}$ Studies with no association in active transport theorised the age of the sibling as the explanation. ${ }^{73-75}$ The lack of association between siblings and active transport may relate to the barriers mentioned in qualitative analysis, that younger siblings may not have the same ability level and may be seen more as a burden than enabler of active transport. The sibling influence on physical activity methods, modalities of sports participation and active commuting confirms the increase in MVPA and reveals that sibling demographics and preferences may create the mixed results in sedentary behaviour.

\section{Hypothesised mechanism of action}

Across studies, it was hypothesised that siblings in the home steer children away from solitary pursuits, decrease sedentary behaviour and raise MVPA. ${ }^{43} 4750$ This finding may support the sex differences, in which females with siblings shift their free time from sedentary pursuits to active pursuits in the presence of a sibling. ${ }^{52} 54$ Siblings 
may also facilitate activity through involvement in active transport ${ }^{40}$ and sport participation by serving as a facilitator and supervision during activity, which also decreases sedentary behaviour, especially in adolescents. ${ }^{42}$ There was no consensus about siblings' influence in afterschool or weekend physical activity, ${ }^{45154}$ indicating there is no single day or period that encompasses the sibling's influence. In contrast, if the siblings prefer sedentary activities or are unmotivated to be active, this peer influence may encourage their siblings to participate in sedentary behaviour instead of MVPA. ${ }^{56}$

As for family structure and parenting practices, one-parent households may force a sibling to serve as a facilitator of physical activity while providing supervision. ${ }^{46}$ In single parent or dual working households, only children may also be encouraged to participate in sedentary activities, since these activities are easier to monitor and frequently considered safer than outdoor or active opportunities. ${ }^{45}$ Choosing these sedentary activities can appease short-term needs, but have long-term impacts on physical activity. Further, only children spend more time in childcare relative to children with siblings and that care may be provided by grandparents. Grandparents may not provide as many physical activity opportunities as a sibling due to the grandparent's potential limited mobility and participation in activities together and may prefer television. ${ }^{45}$ Similarly, grandparents may be more likely to indulge in the child's desires to engage in sedentary behaviour through TV watching. Family structure and dynamics may also be different across cultures and influence the role a sibling may play in caregiving, as evidenced by the difference in sibling influence on physical activity by ethnic groups in McMinn. ${ }^{44}$ The dose response in number of siblings with decreased sedentary behaviour and increased MVPA may be due to an increased likelihood of having a sibling with positive physical activity preferences. ${ }^{41}$ Instead of having one sibling to shape activity preferences, there are multiple children to guide activity preferences, create opportunities and provide supervision of such activities. Further, with more children in the household, there may be less restrictive parenting and a greater chance of siblings serving as caregivers, which may lead to more physical activity opportunities.

The strengths of the current study include the use of objective measures and comparison of intensities between groups. Objective measures help elucidate the influence of the sibling on movement throughout the day and activity intensities, instead of subjective or participation measures. The use of the meta-analytic approach allows a quantitative difference between groups to be determined and referenced to other physical activity standards. Subgroup analysis and dose-response analysis were conducted to determine the difference on subpopulations of young children to better evaluate the sibling influence. The investigation into the mechanism and complexity of sibling relationships aid in contextualising the entire sibling influence on physical activity.
The results from this current meta-analysis may provide a partial explanation for higher obesity rates in only children compared with children with siblings. ${ }^{28} 7677$ Last, this review was conducted using the PRISMA guidelines with a rigorous abstraction and assess risk of bias across all studies, which allows for reproducibility and assessment of study quality.

A limitation of this review is the heterogeneity in defining sibling status and physical activity; not all studies could be compared. Therefore, the meta-analysis may not include all potential estimates of siblings on physical activity. Further, the focus of this paper was on energy balance-related health behaviours and did not address the influence of siblings on underweight or malnutrition, which is explored in less developed nations. ${ }^{78}$ The authors acknowledge that these same behaviours may lead to other health outcomes in only children and children with siblings. The articles retrieved for the meta-analysis were all from developed countries (eg, Canada, USA and UK), where siblings may play a different role in family demands than they do in other developing counties. Further, non-significant results were not presented in most articles. Thus, we could not compare non-significant results in the quantitative portion of this analysis. In many cases, the study measured objective physical activity, but did not record the number of siblings. In visually reviewing the funnel plots, there was no evidence of publication bias. Finally, few studies addressed siblings as an antecedent to physical activity and leading to more physical activity. ${ }^{41}{ }^{50}$ Instead, siblings were analysed as a consequence of physical activity or in posthoc analysis.

Future studies should examine the impact of siblings on children's preferences and opportunities for physical activity. Verloigne noted that children with siblings were less likely to reduce their sedentary time in the intervention, since the children's respective siblings were not motivated to change their sedentary time ${ }^{56}$ Other studies have indicated that the sibling plays a major role in family life style changes for weight loss. ${ }^{79}$ Most family interventions solely include the parent ${ }^{80}$; consequently, in clinical practice it may be important to include the entire family for encouraging physical activity and reducing sedentary behaviours. Only children may need encouragement for peer physical activity through sports participation, since the at home peer influence may not be available. Parents of only children may also need to take a more active role in promoting and facilitating physical activity in the home. Last, it is important to consider other familial factors, such as family structure and grandparent involvement, when creating physical activity opportunities.

In conclusion, this systematic review and meta-analysis suggests that children with siblings have a healthier physical activity pattern with more physical activity and potentially less sedentary behaviour. We found a potential dose response, with more siblings leading to more MVPA, with no differences by age or sex of the child. Proposed mechanisms include siblings serving as peer models, encouraging sports participation and additional 
supervision in physical activity. Sibling involvement in physical activity opportunities may be mediated by the sibling's age and established preference. Considering the influence of the sibling in preference and involvement may lead to more impactful physical activity changes. Overall, all children benefit from physical activity, and siblings may enable more physical activity during childhood.

Acknowledgements We would like to acknowledge Kathy Kyler for her critical review of the article and the Biostatistics and Epidemiology Research Department for their review of the statistical analysis.

Contributors CLK helped develop the idea, conduct the search and abstraction process and wrote majority of the manuscript. SBS helped perfect the idea, assisted in search and abstraction and provided oversight to the project.

Funding The authors have not declared a specific grant for this research from any funding agency in the public, commercial or not-for-profit sectors.

\section{Competing interests None declared.}

Patient consent Not required.

Provenance and peer review Not commissioned; externally peer reviewed.

Data sharing statement The data are available from the authors by request (via email).

Open access This is an Open Access article distributed in accordance with the Creative Commons Attribution Non Commercial (CC BY-NC 4.0) license, which permits others to distribute, remix, adapt, build upon this work non-commercially, and license their derivative works on different terms, provided the original work is properly cited and the use is non-commercial. See: http://creativecommons.org/ licenses/by-nc/4.0/

\section{REFERENCES}

1. Timmons BW, Leblanc AG, Carson V, et al. Systematic review of physical activity and health in the early years (aged 0-4 years). Appl Physiol Nutr Metab 2012;37:773-92.

2. Guo C, Tomson G, Keller C, et al. Prevalence and correlates of positive mental health in Chinese adolescents. BMC Public Health 2018;18:263.

3. Jones RA, Okely AD, Hinkley T, et al. Promoting gross motor skills and physical activity in childcare: a translational randomized controlled trial. J Sci Med Sport 2016;19:744-9.

4. Sævarsson ES, Svansdottir E, Sveinsson T, et al. Organized leisure-time sport participation and academic achievement in preadolescents. Scand J Public Health 2017;45:861-8.

5. Hebert JJ, Møller NC, Andersen LB, et al. Organized sport participation is associated with higher levels of overall healthrelated physical activity in children (CHAMPS Study-DK). PLoS One 2015;10:e0134621.

6. Ferrari GL, Matsudo V, Barreira TV, et al. Correlates of moderateto-vigorous physical activity in Brazilian Children. J Phys Act Health 2016;13:1132-45.

7. Greer AE, Castrogivanni B, Marcello R. Park use and physical activity among mostly low-to-middle income, minority parents and their children. J Phys Act Health 2017;14:83-7.

8. Almanza E, Jerrett M, Dunton G, et al. A study of community design, greenness, and physical activity in children using satellite, GPS and accelerometer data. Health Place 2012;18:46-54.

9. Skinner JD, Carruth BR, Wendy B, Bounds W, et al. Children's food preferences: a longitudinal analysis. J Am Diet Assoc 2002;102:1638-47.

10. Sallis JF, Owen N. ecological models of health behavior. In: Glanz K, Rimer BK, Lewis FM, eds. Health behavior and health education: theory, Research and Practice. 3rd edn. San Francisco, CA: JosseyBass, 2002.

11. Lu C, Stolk RP, Sauer PJ, et al. Factors of physical activity among Chinese children and adolescents: a systematic review. Int J Behav Nutr Phys Act 2017;14:36.

12. Dunton GF, Liao Y, Almanza E, et al. Joint physical activity and sedentary behavior in parent-child pairs. Med Sci Sports Exerc 2012;44:1473-80.

13. Seabra AF, Mendonça DM, Thomis MA, et al. Associations between sport participation, demographic and socio-cultural factors in Portuguese children and adolescents. Eur J Public Health 2008;18:25-30.

14. Spencer RA, Bower J, Kirk SF, et al. Peer mentoring is associated with positive change in physical activity and aerobic fitness of grades 4,5 , and 6 students in the heart healthy kids program. Health Promot Pract 2014;15:803-11.

15. Allison R, Bird EL, McClean S. Is team sport the key to getting everybody active, every day? A systematic review of physical activity interventions aimed at increasing girls' participation in team sport. AIMS Public Health 2017;4:202-20.

16. Mosli RH, Miller AL, Peterson KE, et al. Maternal behavior as a predictor of sibling interactions during mealtimes. Eat Behav 2016;21:76-9.

17. Noonan RJ, Fairclough SJ, Knowles ZR, et al. Context matters! sources of variability in weekend physical activity among families: a repeated measures study. BMC Public Health 2017;17:330.

18. Hesketh KR, Lakshman R, van Sluijs EMF. Barriers and facilitators to young children's physical activity and sedentary behaviour: a systematic review and synthesis of qualitative literature. Obes Rev 2017;18:987-1017.

19. Duch H, Fisher EM, Ensari I, et al. Screen time use in children under 3 years old: a systematic review of correlates. Int $J$ Behav Nutr Phys Act 2013;10:102.

20. Park SH, Cormier E. Influence of siblings on child health behaviors and obesity: a systematic Review. J Child Fam Stud 2018;27:2069-81.

21. Berge JM. A review of familial correlates of child and adolescent obesity: what has the 21st century taught us so far? Int J Adolesc Med Health 2009;21:457-83.

22. Spink KS, Wilson KS, Ulvick J. Social influence and adolescent health-related physical activity in structured and unstructured settings: role of channel and type. Ann Behav Med 2012;44:94-103.

23. Busschaert C, Ridgers ND, De Bourdeaudhuij I, et al. Sociodemographic, social-cognitive, health-related and physical environmental variables associated with context-specific sitting time in belgian adolescents: a one-year follow-up study. PLoS One 2016;11:e0167553.

24. Jalali MS, Sharafi-Avarzaman Z, Rahmandad H, et al. Social influence in childhood obesity interventions: a systematic review. Obes Rev 2016;17:820-32.

25. Meller FO, Loret de Mola C, Assunção MCF, et al. Birth order and number of siblings and their association with overweight and obesity: a systematic review and meta-analysis. Nutr Rev 2018;76:117-24.

26. Oliveira LC, Ferrari GLM, Araújo TL, et al. Overweight, obesity, steps, and moderate to vigorous physical activity in children. Rev Saude Publica 2017;51:38.

27. Marques A, Minderico C, Martins S, et al. Cross-sectional and prospective associations between moderate to vigorous physical activity and sedentary time with adiposity in children. Int $J$ Obes 2016;40:28-33.

28. Ikeda N, Fuse K, Nishi N. Changes in the effects of living with no siblings or living with grandparents on overweight and obesity in children: Results from a national cohort study in Japan. PLoS One 2017;12:e0175726

29. Farooq MA, Parkinson KN, Adamson AJ, et al. Timing of the decline in physical activity in childhood and adolescence: Gateshead Millennium Cohort Study. Br J Sports Med 2017. doi: 10.1136/bjsports-2016-096933. [Epub ahead of print: $13 \mathrm{Mar}$ 2017].

30. Cleland V, Timperio A, Salmon J, et al. A longitudinal study of the family physical activity environment and physical activity among youth. Am J Health Promot 2011;25:159-67.

31. Schofield L, Mummery WK, Schofield G, et al. The association of objectively determined physical activity behavior among adolescent female friends. Res Q Exerc Sport 2007;78:9-15.

32. Senguttuvan $U$, Whiteman $S D$, Jensen $A C$. Family relationships and adolescents' health attitudes and weight: the understudied role of sibling relationships. Fam Relat 2014;63:384-96.

33. Liberati A, Altman DG, Tetzlaff J, et al. The PRISMA statement for reporting systematic reviews and meta-analyses of studies that evaluate health care interventions: explanation and elaboration. $J$ Clin Epidemiol 2009;62:e1-e34.

34. Dubois L, Ohm Kyvik K, Girard M, et al. Genetic and environmental contributions to weight, height, and BMI from birth to 19 years of age: an international study of over 12,000 twin pairs. PLoS One 2012;7:e30153.

35. Kahn LG, Buka SL, Cirillo PM, et al. Evaluating the relationship between birth weight for gestational age and adult blood pressure using participants from a cohort of same-sex siblings, discordant on birth weight percentile. Am J Epidemiol 2017;186:550-4. 
36. Van Schoors M, De Mol J, Morren H. Parents' perspectives of changes within the family functioning after a pediatric cancer diagnosis: a multi family member interview Analysis. Qual Health Res 2018:28:1229-41.

37. Psota TL, Spill M, Spahn J. Advancing systematic review methodology to better inform food and nutrition policy. The FASEB Journal 2016;30(Suppl 1):131.

38. Peterson RA, Brown SP. On the use of beta coefficients in metaanalysis. J Appl Psychol 2005;90:175-81.

39. Higgins JP, Thompson SG. Quantifying heterogeneity in a metaanalysis. Stat Med 2002;21:1539-58.

40. Mitchell CA, Clark AF, Gilliland JA. Built environment influences of children's physical activity: examining differences by neighbourhood size and sex. Int J Environ Res Public Health 2016;13:130.

41. Gomes TN, Hedeker D, Dos Santos FK, et al. Relationship between sedentariness and moderate-to-vigorous physical activity in youth: a multivariate multilevel study. Int J Environ Res Public Health 2017:14:148.

42. Gomes TN, dos Santos FK, Santos D, et al. Correlates of sedentary time in children: a multilevel modelling approach. BMC Public Health 2014:14:890

43. Hnatiuk JA, Hesketh KR, van Sluijs EM. Correlates of home and neighbourhood-based physical activity in UK 3-4-year-old children. Eur J Public Health 2016;26:947-53.

44. McMinn AM, van Sluijs EMF, Nightingale CM, et al. Family and home correlates of children's physical activity in a multi-ethnic population: the cross-sectional child heart and health study in england (CHASE) Int J Behav Nutr Phys Act 2011;8:11.

45. Wang L, Qi J. Association between family structure and physical activity of Chinese adolescents. Biomed Res Int 2016;2016:4278682-7.

46. Hesketh K, Crawford D, Salmon J. Children's television viewing and objectively measured physical activity: associations with family circumstance. Int J Behav Nutr Phys Act 2006;3:36

47. van Sluijs EM, McMinn AM, Inskip HM, et al. Correlates of light and moderate-to-vigorous objectively measured physical activity in fouryear-old children. PLoS One 2013;8:e74934.

48. Pouliou T, Sera F, Griffiths L, et al. Environmental influences on children's physical activity. J Epidemiol Community Health 2015;69:77-85.

49. Atkin $\mathrm{AJ}$, Corder $\mathrm{K}$, Ekelund $\mathrm{U}$, et al. Determinants of change in children's sedentary time. PLoS One 2013;8:e67627.

50. Wijtzes Al, Kooijman MN, Kiefte-de Jong JC, et al. Correlates of physical activity in 2-year-old toddlers: the generation $\mathrm{R}$ study. $J$ Pediatr 2013;163:791-9.

51. Tandon P, Grow HM, Couch S, et al. Physical and social home environment in relation to children's overall and home-based physical activity and sedentary time. Prev Med 2014;66:39-44.

52. Hinkley T, Salmon J, Okely AD, et al. Correlates of preschool children's physical activity. Am J Prev Med 2012;43:159-67.

53. Byun W, Dowda M, Pate RR. Correlates of objectively measured sedentary behavior in US preschool children. Pediatrics 2011:128:937-45

54. Pearce M, Page AS, Griffin TP, et al. Who children spend time with after school: associations with objectively recorded indoor and outdoor physical activity. Int J Behav Nutr Phys Act 2014;11:45.

55. Crawford $D$, Cleland $V$, Timperio $A$, et al. The longitudinal influence of home and neighbourhood environments on children's body mass index and physical activity over 5 years: the CLAN study. Int $J$ Obes 2010;34:1177-87

56. Verloigne M, Bere E, Van Lippevelde $\mathrm{W}$, et al. The effect of the UP4FUN pilot intervention on objectively measured sedentary time and physical activity in 10-12 year old children in Belgium: the ENERGY-project. BMC Public Health 2012;12:805.

57. Bagley S, Salmon J, Crawford D. Family structure and children's television viewing and physical activity. Med Sci Sports Exerc 2006;38:910-8.

58. McMinn AM, Griffin SJ, Jones AP, et al. Family and home influences on children's after-school and weekend physical activity. Eur $J$ Public Health 2013;23:805-10.

59. Silva DR, Fernandes RA, Ohara D, et al. Correlates of sports practice, occupational and leisure-time physical activity in Brazilian adolescents. Am J Hum Biol 2016;28:112-7.
60. Fernandes RA, Reichert FF, Monteiro HL, et al. Characteristics of family nucleus as correlates of regular participation in sports among adolescents. Int J Public Health 2012;57:431-5.

61. Edwards MJ, Jago R, Sebire SJ, et al. The influence of friends and siblings on the physical activity and screen viewing behaviours of children aged 5-6 years: a qualitative analysis of parent interviews. BMJ Open 2015;5:e006593.

62. Hohepa M, Scragg R, Schofield G, et al. Social support for youth physical activity: Importance of siblings, parents, friends and school support across a segmented school day. Int J Behav Nutr Phys Act 2007;4:54.

63. Dong F, Howard AG, Herring AH, et al. Parent-child associations for changes in diet, screen time, and physical activity across two decades in modernizing China: China Health and Nutrition Survey 1991-2009. Int J Behav Nutr Phys Act 2016:13:118.

64. Li M, Xue H, Wang W, et al. Increased obesity risks for being an only child in China: findings from a nationally representative study of 19,487 children. Public Health 2017;153:44-51.

65. Li M, Xue H, Wang W, et al. Parental Expectations and Child Screen and Academic Sedentary Behaviors in China. Am J Prev Med 2017:52:680-9.

66. Blazo JA, Czech DR, Carson S, et al. A qualitative investigation of the sibling sport achievement experience. Sport Psychol 2014;28:36-47.

67. Wright MS, Wilson DK, Griffin S, et al. A qualitative study of parental modeling and social support for physical activity in underserved adolescents. Health Educ Res 2010;25:224-32.

68. Azevedo KJ, Mendoza S, Fernández M, et al. Turn off the TV and dance! Participation in culturally tailored health interventions: implications for obesity prevention among Mexican American girls. Ethn Dis 2013;23:452-61.

69. Hornby-Turner YC, Hampshire KR, Pollard TM. A comparison of physical activity and sedentary behaviour in 9-11 year old British Pakistani and White British girls: a mixed methods study. Int J Behav Nutr Phys Act 2014;11:74.

70. Pabayo RA, Gauvin L, Barnett TA, et al. Understanding the determinants of active transportation to school among children: evidence of environmental injustice from the Quebec Longitudinal Study of Child Development. Health Place 2012;18:163-71.

71. Pabayo R, Gauvin L, Barnett TA. Longitudinal changes in active transportation to school in Canadian youth aged 6 through 16 years. Pediatrics 2011;128:e404-e413.

72. Van Hecke L, Verhoeven H, Clarys P, et al. Factors related with public open space use among adolescents: a study using GPS and accelerometers. Int J Health Geogr 2018;17:3.

73. Janssen I, Ferrao T, King N. Individual, family, and neighborhood correlates of independent mobility among 7 to 11 -year-olds. Prev Med Rep 2016:3:98-102.

74. Cardon GM, Maes L RD, Haerens LL, et al. Bicycling to school during the transition from childhood into adolescence: a six-year longitudinal study. Pediatr Exerc Sci 2012;24:369-83.

75. Gropp KM, Pickett W, Janssen I. Multi-level examination of correlates of active transportation to school among youth living within 1 mile of their school. Int J Behav Nutr Phys Act 2012;9:124

76. Chen AY, Escarce JJ. Family structure and childhood obesity, early childhood longitudinal study - Kindergarten Cohort. Prev Chronic Dis 2010;7:A50.

77. Chen AY, Escarce JJ, Structure F. Family structure and childhood obesity: an analysis through 8th grade. Matern Child Health $J$ 2014;18:1772-7.

78. Helfrecht C, Meehan CL. Sibling effects on nutritional status: Intersections of cooperation and competition across development. Am J Hum Biol 2016;28:159-70.

79. Eg M, Frederiksen $\mathrm{K}$, Vamosi M, et al. How family interactions about lifestyle changes affect adolescents' possibilities for maintaining weight loss after a weight-loss intervention: a longitudinal qualitative interview study. J Adv Nurs 2017;73:1924-36.

80. Ash T, Agaronov A, Young T, et al. Family-based childhood obesity prevention interventions: a systematic review and quantitative content analysis. Int J Behav Nutr Phys Act 2017;14:113. 